\title{
Diversidade genética e eficiência de DNA microssatélites para o controle genealógico da raça Nelore
}

[Genetic diversity and efficiency of DNA microsatellites for genealogic control in Nelore breed]

\author{
T.X. Carneiro, E.C. Gonçalves, M.P.C. Schneider, A. Silva
}

Departamento de Genética - UFPA

Rua Augusto Corrêa, 1

66075-110, Belém-PA

\begin{abstract}
RESUMO
Foram estimados na raça Nelore a variabilidade genética e os valores de determinação de paternidade usando-se 11 marcadores microssatélites do painel ISAG/FAO. Estes foram organizados em quatro conjuntos de amplificação para genotipagem semi-automática por fluorescência. Todos os marcadores apresentaram-se altamente polimórficos, com média de 8,2 alelos por loco. A heterozigosidade observada, com média de 0,48 , foi menor que a esperada em 10 locos. Foram observadas deficiências de heterozigotos em nove locos, o que resultou no desequilíbrio de Hardy-Weinberg para a população estudada. O conteúdo polimórfico informativo foi superior a $0,5 \mathrm{em} 10$ locos. O poder de discriminação foi $>0,999$ e as probabilidades de exclusão de paternidade quando são conhecidos os genótipos de um bezerro, sua mãe e um pai alegado, ou quando um ou outro genótipo parental não está disponível, para o conjunto de marcadores foram $>0,999$ e $>0,989$, respectivamente. O conjunto de 11 marcadores constitui método eficiente para a determinação de paternidade na raça Nelore.
\end{abstract}

Palavras-chave: bovino, Nelore, microssatélite, variabilidade genética, teste de paternidade

\begin{abstract}
The genetic variability and paternity testing values in Nelore breed were estimated using 11 ISAG/FAO microsatellites. The markers were organized into 4 amplification groups for semi-automated fluorescence genotyping. All markers were highly polymorphic, with an average of 8.2 alleles per locus. With a mean value of 0.48 , the observed heterozygosity was lower than the expected for 10 of the loci. A significant deficit of heterozygotes was observed for 9 loci, resulting in a lack of Hardy-Weinberg equilibrium in the studied population. Polymorphism information content values exceeded 0.5 for 10 loci. The power of discrimination was $>0.999$ and paternity exclusion probabilities when a mother, her offspring and a putative sire are compared or when one or other parental genotype is unavailable for the combined set of markers were, respectively, $>0.999$ and $>0.989$. The set of 11 microsatellite markers proved to be an efficient tool for paternity testing in Nelore cattle.
\end{abstract}

Keywords: cattle, Nelore, microsatellite, genetic variation, paternity testing

\section{INTRODUÇÃO}

O melhoramento genético a que as espécies domésticas têm sido submetidas visa, principalmente, selecionar multiplicar e distribuir os animais com características favoráveis, para tornar os rebanhos mais produtivos. A seleção direcionada, associada à utilização de poucos reprodutores para diversas matrizes, resulta em elevação dos coeficientes de endocruzamento e redução do tamanho populacional efetivo e da variabilidade genética (Falconer e Mackay, 1996; Mateus et al., 2004).

Recebido em 2 de janeiro de 2006

Aceito em 21 de agosto de 2007

E-mail: thomazx@gmail.com 
A perda contínua de diversidade genética de uma raça reduz a possibilidade de futuro melhoramento genético (Eding, 2001). A utilização de uma única população em detrimento de um grupo de linhagens amplia as oportunidades de deriva genética e perdas, ao acaso, de alelos neutros ou levemente favoráveis (Notter, 1999).

Apesar de a população da raça Holstein Friesian americana exceder de 10 milhões de animais, seu tamanho populacional efetivo é estimado como inferior a 1000 indivíduos, resultado principalmente do uso sistemático de inseminação artificial de um pequeno plantel de machos de elite (Georges e Andersson, 1996). Coeficientes de endocruzamento para a raça também são elevados, entre 2 e $5 \%$, e podem levar a valores ainda menores de tamanho efetivo (Machugh et al., 1998). Efeitos indesejáveis do endocruzamento incluem redução na produção de leite e na contagem de células somáticas (Notter, 1999), e recentemente foi documentada redução na eficiência reprodutiva, observando-se em gado leiteiro, a cada $1 \%$ de aumento de endocruzamento, a elevação na idade do primeiro parto em 0,4 dia, o aumento no intervalo de parto em 0,3 dia e o decréscimo de período de vida em 13 dias (Lucy, 2001; Weigel et al., 2001).

Os marcadores nucleares microssatélites são importantes ferramentas para o estudo de genética de populações e de relações de paternidade e parentesco genético, pela codominância, abundância nos genomas e alto nível de polimorfismo (Glowatzki-Mullis et al., 1995; Machugh et al., 1998).

Informações de paternidade acuradas são fundamentais para a estimativa dos valores genéticos dos animais (Baron et al., 2002). As taxas de erro de identificação de paternidade em várias raças bovinas no mundo variam de $5 \mathrm{a}$ $23 \%$, e provocam viés na estimativa de parâmetros genéticos e de valores de melhoramento e progresso de seleção genética (Van Vleck, 1970; Ron et al., 1996; Israel e Weller, 2000; Banos et al., 2001). Banos et al. (2001) introduziram experimentalmente $11 \%$ de erro de identificação de paternidade no banco de dados de avaliação genética norte-americano do gado Holstein sob fertilização artificial e observaram $11-15 \%$ de decréscimo nas tendências genéticas estimadas, com redução de valores de melhoramento de cerca de $50 \mathrm{~kg}$ de leite e $1,7 \mathrm{~kg}$ de proteína.

Os objetivos deste estudo foram avaliar a variabilidade genética e a estimativa de determinação de paternidade em gado Nelore, utilizando marcadores microssatélites de comparabilidade internacional.

\section{MATERIAL E MÉTODOS}

Foram coletadas amostras de sangue de 50 indivíduos da raça Nelore, 15 machos puros de origem (PO) e 35 fêmeas livro aberto (LA), não aparentados, do Estado do Pará. O DNA genômico foi isolado por meio de protocolo adaptado de Sambrook et al. (1989). Foram amplificados, por reação em cadeia da polimerase (PCR), 11 marcadores microssatélites, não-ligados, recomendados pela ISAG/FAO para estudos de diversidade e paternidade em bovinos: TGLA53, TGLA122, TGLA126, TGLA227, ETH3, ETH10, ETH225, BM1824, BM2113, INRA23 e SPS115 (FAO..., 2004). As seqüências dos iniciadores e respectivas referências bibliográficas e posições de mapa podem ser encontradas no Sistema de Informações de Diversidade de Animais Domésticos da FAO-ONU (http://www.fao.org/dad_is).

Os 11 microssatélites analisados foram amplificados em quatro conjuntos independentes, com dois ou três locos amplificados simultaneamente (Tab. 1), sendo uma fita do par de iniciadores marcada com o fluocromo Cy5. Todas as reações de PCR foram realizadas para volume final de $20 \mu$ l contendo: 150 ng de DNA, $0,25 \mathrm{mM}$ de cada dNTP, 0,5U de Taq DNA Polimerase (Invitrogen), 50mM KCL, $10 \mathrm{mM}$ Tris-HCL ( $\mathrm{pH} 8,4), 1 \mathrm{mM}$ de $\mathrm{MgCl}_{2}$ e $0,25 \mu \mathrm{lde}$ formamida (Sigma). A concentração dos iniciadores foi variável (Tab. 1). As reações de PCR foram realizadas em termociclador PTC200 (MJ Research) seguindo o método touchdown de otimização, composto por: um passo de desnaturação inicial a $96^{\circ} \mathrm{C}$ por três minutos, 10 ciclos a $94^{\circ} \mathrm{C}$ por 45 segundos, 45 segundos a 60 (conjunto 1) ou $62^{\circ} \mathrm{C}$ (conjuntos restantes) decrescentes em $0,5^{\circ} \mathrm{C}$ por ciclo e 45 segundos a $72^{\circ} \mathrm{C} ; 20$ (conjunto 2 ) ou 24 ciclos (conjuntos restantes) de 45 segundos a $90^{\circ} \mathrm{C}, 45$ segundos a 57 (conjunto 1 ) ou $58^{\circ} \mathrm{C}$ (conjuntos 
restantes) e 45 segundos a $72^{\circ} \mathrm{C}$; cinco minutos a $72^{\circ} \mathrm{C}$ para extensão final.

Tabela 1. Descrição dos conjuntos de marcadores e concentração dos iniciadores utilizados para genotipagem de marcadores microssatélites em bovinos da raça Nelore

\begin{tabular}{ccc} 
Conjunto & Loco & $\begin{array}{c}\text { Concentração } \\
\text { dos iniciadores } \\
(\mathrm{pM})\end{array}$ \\
\hline \multirow{2}{*}{1} & TGLA126 & 0,270 \\
& ETH225 & 0,102 \\
2 & BM1824 & 0,150 \\
& BM2113 & 0,270 \\
\multirow{2}{*}{3} & INRA23 & 0,270 \\
& TGLA227 & 0,210 \\
& TGLA53 & 0,300 \\
& SPS115 & 0,045 \\
4 & ETH3 & 0,090 \\
& TGLA122 & 0,180 \\
& ETH10 & 0,090 \\
\hline
\end{tabular}

Os fragmentos amplificados foram separados por eletroforese vertical em gel de poliacrilamida $8 \%$ no analisador automático de DNA ALF Express II (GE Healthcare), com utilização de padrões internos e externos fornecidos pelo fabricante. A definição do tamanho dos alelos foi realizada no aplicativo AlleleLocator 1.03 (GE Healthcare).

O aplicativo POPGENE 1.32 (Yeh et al., 1997) foi utilizado para calcular as freqüências alélicas, número observado de alelos (Na; Nei, 1987), número efetivo de alelos (Ne; Kimura e Crow, 1964), e heterozigosidades observada (Ho) e esperada $(\mathrm{He})$, para cada marcador. Desvios do equilíbrio de Hardy-Weinberg foram calculados no aplicativo GENEPOP 3.1 (Raymond $\mathrm{e}$ Rousset, 1995) para a população, utilizando-se o método de Fisher. O mesmo aplicativo foi utilizado para testar a deficiência de heterozigotos para a população e por loco, por meio da estimativa não-enviesada de probabilidades exatas, pelo método de cadeia de Markov (Guo e Thompson, 1992).

Os cálculos do poder de discriminação (PD; Jones, 1972) e conteúdo polimórfico informativo (PIC; Botstein et al., 1980) foram obtidos utilizando o aplicativo PowerStats v1.2
(Promega). A probabilidade de exclusão (PE) foi calculada para dois casos: PE1 quando os genótipos de uma mãe, seu filho e um pai alegado são comparados, calculada por meio da fórmula 1a de Jamieson e Taylor (1997), e apropriada para quando a matriz é confirmada como mãe no momento do nascimento; e PE2, quando não está disponível um ou outro genótipo parental, calculada segundo a fórmula simplificada 2a de Jamieson e Taylor (1997), com base em Garber e Morris (1983). Os valores por loco de PD, PE1 e PE2 foram combinados para a população por meio da fórmula $\mathrm{P}=1-(1-$ $\left.\mathrm{P}_{1}\right)\left(1-\mathrm{P}_{2}\right)\left(1-\mathrm{P}_{3}\right)^{\cdots}\left(1-\mathrm{P}_{\mathrm{k}}\right)$, para $\mathrm{k}$ número de locos.

\section{RESULTADOS E DISCUSSÃO}

Quatro conjuntos para amplificação simultânea, abrangendo 11 locos microssatélites, foram elaborados e avaliados para análise de diversidade e parentesco na raça Nelore.

Os alelos observados, por marcador microssatélite, e suas respectivas freqüências estão apresentados na Tab. 2. As medidas baseadas em freqüências alélicas, $\mathrm{Na}$ e $\mathrm{Ne}$, Ho e He, PIC e PD, e PEI e PE2 são apresentadas na Tab. 3. Todos os locos mostraram-se polimórficos. O Na variou de 4 (TGLA227 e ETH10) a 13 (TGLA53), com média de 8,2 alelos por loco, e o Ne variou de 1,4 (TGLA227) a 7,7 (TGLA122), com média de 3,9.

A Ho apresentou valor mínimo de 0,22 (ETH10) e máximo de 0,92 (TGLA122), com média de 0,49, inferior ao esperado para todos os locos exceto TGLA122. O PIC apresentou valor médio de 0,64 , variando de 0,28 (TGLA227) a 0,85 (TGLA122), sendo todos (exceto TGLA227) acima de 0,5. Esse índice permite avaliar cada loco quanto ao grau de informação em estudos de segregação alélica e valores abaixo de 0,5 são considerados pouco informativos (Botstein et al., 1980). Valores altos de heterozigosidade $(0,88)$ e PIC $(0,86)$ para TGLA122 também foram evidenciados por Almeida et al. (2000), em Brangus Ibagé, sendo o único loco coincidente com o deste estudo. Em Gir, Rodrigues et al. (2002), para o único loco coincidente com o deste estudo, BM2113, observaram Ho mais elevada $(0,82$ contra 0,58$)$, mas valores similares de alelos (sete alelos encontrados), PIC, PE1 e PE2. 


\section{Carneiro et al.}

Tabela 2. Microssatélites utilizados, tamanho dos alelos observados e freqüências observadas (\%) na raça Nelore

\begin{tabular}{|c|c|c|c|c|c|c|c|c|c|c|}
\hline TGLA126 & ETH225 & BM1824 & BM2113 & INRA23 & TGLA227 & TGLA53 & SPS115 & ETH3 & TGLA122 & ETH10 \\
\hline $118(0,06)$ & $139(0,10)$ & $180(0,29)$ & $128(0,08)$ & $195(0,04)$ & $80(0,82)$ & $153(0,03)$ & $243(0,20)$ & $102(0,05)$ & $137(0,12)$ & $208(0,46)$ \\
\hline $120(0,04)$ & $143(0,04)$ & $182(0,47)$ & $130(0,24)$ & $197(0,06)$ & $82(0,12)$ & $159(0,42)$ & $245(0,57)$ & $104(0,01)$ & $139(0,12)$ & $210(0,38)$ \\
\hline $122(0,09)$ & $145(0,03)$ & $184(0,14)$ & $134(0,06)$ & $199(0,16)$ & $84(0,02)$ & $161(0,02)$ & $247(0,04)$ & $114(0,05)$ & $143(0,08)$ & $212(0,12)$ \\
\hline $124(0,42)$ & $147(0,01)$ & $190(0,01)$ & $136(0,13)$ & $201(0,02)$ & $86(0,04)$ & $167(0,14)$ & $251(0,05)$ & $116(0,46)$ & $145(0,17)$ & $218(0,04)$ \\
\hline $126(0,28)$ & $149(0,01)$ & $192(0,01)$ & $140(0,12)$ & $203(0,14)$ & & $169(0,09)$ & $253(0,11)$ & $118(0,36)$ & $147(0,03)$ & \\
\hline $128(0,05)$ & $151(0,01)$ & $194(0,03)$ & $142(0,26)$ & $205(0,09)$ & & $171(0,03)$ & $255(0,03)$ & $126(0,07)$ & $149(0,08)$ & \\
\hline $130(0,05)$ & $153(0,04)$ & $196(0,04)$ & $144(0,11)$ & $209(0,05)$ & & $175(0,01)$ & & & $151(0,01)$ & \\
\hline \multirow[t]{6}{*}{$132(0,01)$} & $155(0,13)$ & $198(0,01)$ & & $210(0,01)$ & & $177(0,02)$ & & & $153(0,03)$ & \\
\hline & $157(0,61)$ & & & $211(0,03)$ & & $181(0,01)$ & & & $155(0,14)$ & \\
\hline & $159(0,02)$ & & & $213(0,07)$ & & $183(0,01)$ & & & $161(0,01)$ & \\
\hline & & & & $215(0,28)$ & & $185(0,01)$ & & & $163(0,19)$ & \\
\hline & & & & $217(0,05)$ & & $187(0,20)$ & & & $171(0,02)$ & \\
\hline & & & & & & $189(0,01)$ & & & & \\
\hline
\end{tabular}

Freqüência entre parêntesis.

Tabela 3. Número de alelos, heterozigosidade, conteúdo polimórfico informativo, poder de discriminação e probabilidades de exclusão, por loco, observados na raça Nelore

\begin{tabular}{lllllll} 
Loco & $\mathrm{Na}(\mathrm{Ne})$ & $\mathrm{Ho}(\mathrm{He})$ & $\mathrm{PIC}$ & PD & PE1 & PE2 \\
\hline TGLA126 & $8(3,66)$ & $0,50(0,734)$ & 0,690 & 0,857 & 0,512 & 0,334 \\
ETH225 & $10(2,47)$ & $0,28(0,602)$ & 0,572 & 0,686 & 0,400 & 0,216 \\
BM1824 & $8(3,05)$ & $0,50(0,679)$ & 0,622 & 0,824 & 0,428 & 0,260 \\
BM2113 & $7(5,59)$ & $0,58(0,829)$ & 0,798 & 0,906 & 0,647 & 0,473 \\
INRA23 & $12(6,74)$ & $0,72(0,860)$ & 0,837 & 0,940 & 0,713 & 0,551 \\
TGLA227 & $4(1,45)$ & $0,24(0,314)$ & 0,289 & 0,479 & 0,162 & 0,049 \\
TGLA53 & $13(4,04)$ & $0,74(0,760)$ & 0,725 & 0,889 & 0,559 & 0,376 \\
SPS115 & $6(2,61)$ & $0,36(0,624)$ & 0,579 & 0,742 & 0,395 & 0,221 \\
ETH3 & $6(2,84)$ & $0,36(0,655)$ & 0,587 & 0,791 & 0,391 & 0,235 \\
TGLA122 & $12(7,77)$ & $0,92(0,880)$ & 0,858 & 0,954 & 0,741 & 0,586 \\
ETH10 & $4(2,68)$ & $0,22(0,634)$ & 0,555 & 0,707 & 0,351 & 0,207 \\
Média & $8,18(3,905)$ & $0,49(0,311)$ & 0,647 & & & \\
\hline
\end{tabular}

Na: número de alelos observados; Ne: número de alelos efetivos; Ho: heterozigosidade observada; He: heterozigosidade esperada; PIC: conteúdo polimórfico informativo; PD: poder de discriminação; PE1: probabilidade de exclusão quando são relacionados genótipos de um progenitor, um bezerro e um progenitor alegado; PE2: probabilidade de exclusão quando um ou outro genótipo parental não está disponível.

Peelman et al. (1998) observaram, para a raça Belgian Blue, Ne médio de 3,93, semelhante ao encontrado neste estudo, contudo a Ho média, de 0,65 , foi mais alta que a encontrada em Nelore $(0,49)$. Martin-Burriel et al. (1999), Maudet et al. (2002), Rendo et al. (2004) e Radko et al. (2005) também observaram valores de Ho mais elevados (entre 0,60 e 0,75) que os verificados neste estudo, ao utilizarem raças autóctones em extinção, raças de tamanho populacional médio ou raças de ampla representação.

Os baixos valores de heterozigosidade encontrados por este estudo refletiram nos testes 
de equilíbrio populacional. No teste global (teste de Fisher), a população apresentou-se sob desequilíbrio de Hardy-Weinberg. Sob estimativa de valores exatos de probabilidade de Hardy-Weinberg, a população apresentou significância $(\mathrm{P}<0,01)$ para deficiência de heterozigotos e quando analisado cada marcador, oito locos $(73 \%)$ apresentaram deficiência de heterozigotos. Este resultado é interessante pois relata número de locos com deficiência de heterozigotos acima do encontrado em raças sob risco de extinção (Martin-Burriel et al., 1999; Maudet et al., 2002). Maudet et al. (2002) identificaram situação semelhante na raça Holstein e, assim, para raças com populações grandes e pouco isoladas, como Nelore e Holstein. Tais resultados podem ser explicados pelos muitos cruzamentos preferenciais e endocruzamentos. Em raças submetidas a isolamento geográfico e com pequena população, a deriva genética e o efeito Wahlund (subdivisão populacional) parecem mais prováveis para explicar a baixa variabilidade e a ocorrência de desequilíbrio populacional (Martin-Burriel et al., 1999; Maudet et al., 2002).

O poder de discriminação, índice desenvolvido por Jones (1972) e associado à probabilidade de combinação (Huston, 1998), foi altamente favorável para o sistema. A PE1 combinada para todos os locos foi maior que 0,999, demonstrando a eficiência dos 11 marcadores utilizados para a análise de paternidade. A PE2 combinada para todos os locos foi de 0,989, necessitando marcador adicional ou de análise de verossimilhança com os pais não excluídos (Marshall et al., 1998).

\section{CONCLUSÕES}

A reduzida variabilidade genética na raça Nelore, evidenciada por meio dos baixos níveis de heterozigosidade e ausência de equilíbrio de Hardy-Weinberg, sugere depressão populacional por endocruzamento devido ao manejo reprodutivo utilizado. Espera-se contribuir para o conhecimento genético dos rebanhos bovinos brasileiros e para as estratégias utilizadas no manejo dessas populações. O conjunto de 11 marcadores microssatélites indicados pela ISAG/FAO mostrou-se eficiente para a verificação de paternidade para fins de melhoramento genético na raça Nelore.

\section{AGRADECIMENTOS}

Os autores agradecem ao Conselho Nacional de Desenvolvimento Científico e Tecnológico (CNPq), em conjunto com a Secretaria Executiva de Ciência Tecnologia e Meio Ambiente do Estado do Pará (SECTAM), pelo suporte através do Programa de Apoio a Núcleos de Excelência (PRONEX) e pela bolsa de iniciação científica.

\section{REFERÊNCIAS BIBLIOGRÁFICAS}

ALMEIDA, S.E.M.; MACHADO, M.S.N.; STEIGLEDER, C.S. et al. Genetic diversity in a Brazilian bovine herd based on four microsatellite loci. Genet. Mol. Biol., v.23, p.347-350, 2000.

BANOS, G.; WIGGANS, G.R.; POWELL, R.L. Impact of paternity errors in cow identification on genetic evaluations and international comparisons. $J$. Dairy Sci., v.84, p.2523-2529, 2001.

BARON, E.E.; MARTINEZ, M.L.; VERNEQUE, R.S. et al. Parentage testing and effect of misidentification on the estimation of breeding value in Gir cattle. Genet. Mol. Biol., v.25, p.389-394, 2002.

BOTSTEIN, D.; WHITE, R.L.; SKOLNICK, M. et al. Construction of a genetic linkage map in man using restriction fragment length polymorphisms. Am. J. Hum. Genet., v.32, p.314-331, 1980.

EDING, H. Conservation of genetic diversity: assessing genetic variation using marker estimated kinships. 2001. 79f. Tese (Doutorado em Ciência Animal) - Department of Animal Sciences, Wageningen University, Wageningen.

FALCONER, D.S.; MACKAY, T.F.C. Introduction to quantitative genetics. Harlow: Longman House, 1996.

FAO. Secondary guidelines for development of national farm animal genetic resources management plans: measurement of domestic animal diversity (MoDAD): recommended microsatellite markers. Roma:FAO/UNEP/IDAD-ONU 2004.

GARBER, R.A.; MORRIS, J.W. General equations for the average power of exclusion for genetic systems of $\mathrm{n}$ codominant alleles in one-parent aand no-parent cases of disputed parentage. In: WALKER, R.H. (Ed.). Inclusion probabilities in parentage testing. Arlington: American Association of Blood Banks, 1983. p.277280.

GEORGES, M.; ANDERSSON, L. Livestock genomics comes of age. Genome Res., v.6, p.907-921, 1996. 


\section{Carneiro et al.}

GLOWATZKI-MULLIS, M.L.; GAILLARD， C.; WIGGER, G. et al. Microsatellite-based parentage control in cattle. Anim. Genet., v.26, p.7-12, 1995.

GUO, S.W.; THOMPSON, E.A. Performing the exact test of Hardy-Weinberg proportion for multiple alleles. Biometrics, v.48, p.361-372, 1992.

HUSTON, K.A. Statistical analysis of STR data. Profiles DNA, v.103, p.14-15, 1998.

ISRAEL, C.; WELLER, J.I. Effect of misidentification on genetic gain and estimation of breeding value in dairy cattle populations. J. Dairy Sci., v.83, p.181-187, 2000.

JAMIESON, A.; TAYLOR, S.C. Comparisons of three probability formulae for parentage exclusion. Anim. Genet., v.28, p.397-400, 1997.

JONES, D.A. Blood samples - probability of discrimination. J. Forensic. Sci. Soc., v.12, p.355-359, 1972.

KIMURA, M.; CROW, J.F. Number of alleles that can be maintained in finite population. Genetics, v.49, p.725-738, 1964

LUCY, M.C. Reproductive loss in high-producing dairy cattle: where will it end? J. Dairy Sci., v.84, p.1277-1293, 2001.

MACHUGH, D.E.; LOFTUS, R.T.; CUNNINGHAM, P. et al. Genetic structure of seven European cattle breeds assessed using 20 microsatellite markers. Anim. Genet., v.29, p.333-340, 1998.

MARSHALL, T.C.; SLATE, J.; KRUUK, L.E.B. et al. Statistical confidence for likelihood-based paternity inference in natural populations. Mol. Ecol., v.7, p.639-655, 1998 .

MARTIN-BURRIEL， I.; GARCIA-MURO, E.; ZARAGOZA, P. Genetic diversity analysis of six Spanish native cattle breeds using microsatellites. Anim. Genet., v.30, p.177-182, 1999.

MATEUS, J.C.; EDING, H.; PENEDO, M.C. et al. Contributions of Portuguese cattle breeds to genetic diversity using marker-estimated kinships. Anim. Genet., v.35, p.305-313, 2004.

MAUDET, C.; LUIKART, G.; TABERLET, P. Genetic diversity and assignment tests among seven French cattle breeds based on microsatellite DNA analysis. J. Anim. Sci., v.80, p.942-950, 2002.
NEI, M. Molecular evolutionary genetics. New York: Columbia University, 1987.

NOTTER, D.R. The importance of genetic diversity in livestock populations of the future. J. Anim. Sci., v.77, p.61-69, 1999 .

PEELMAN, L.J.; MORTIAUX, F.; VAN ZEVEREN, A. et al. Evaluation of the genetic variability of 23 bovine microsatellite markers in four Belgian cattle breeds. Anim. Genet., v.29, p.161-167, 1998.

RADKO, A.; ZYGA, A.; ZABEK, T. et al. Genetic variability among Polish Red, Hereford and HolsteinFriesian cattle raised in Poland based on analysis of microsatellite DNA sequences. J. Appl. Genet., v.46, p.89-91, 2005.

RAYMOND, M.; ROUSSET, F. Genepop (Version1.2) - Population-Genetics Software for Exact Tests and Ecumenicism. J. Hered., v.86, p.248-249, 1995.

RENDO, F.; IRIONDO, M.; JUGO, B.M. et al. Analysis of the genetic structure of endangered bovine breeds from the Western Pyrenees using DNA microsatellite markers. Biochem. Genet., v.42, p.99108, 2004.

RODRIGUES, S.G.; OLIVEIRA, D.A.A.; TEIXEIRA, C.S. et al. Microssatélites BM2113, ILSTS005, ILSTS008, ETH131 e RM88 em testes de verificação de parentesco para bovinos da raça Gir. Arq. Bras. Med. Vet. Zootec., v.54, p.309-313, 2002.

RON, M.; BLANC, Y.; BAND, M. et al. Misidentification rate in the Israeli dairy cattle population and its implications for genetic improvement. J. Dairy Sci., v.79, p.676-681, 1996.

SAMBROOK, J.; FRITCH, E.F.; MANIATIS, T. Molecular cloning: a laboratory manual. Cold Spring Harbor: Cold Spring Harbor Laboratory, 1989.

VAN VLECK, L.D. Misidentification and sire evaluation. J. Dairy Sci., v.53, p.1697-1702, 1970.

WEIGEL, K.A.; REKAYA, R.; ZWALD, N.R. et al. International genetic evaluation of dairy sires using a multiple-trait model with individual animal performance records. J. Dairy Sci., v.84, p.2789-2795, 2001 .

YEH, F.C.; YANG, R.C.; BOYLE, T.B.J. et al. POPGENE (version 1.32): Software Microsoft Windows-based freeware for population genetics analysis. Alberta: University of Alberta, 1997. 